\title{
Multi-Parametric Characterization of Amino Acid- and Peptide-Silica Stationary Phases
}

\author{
${\text { Bogusław Buszewski }{ }^{1} \text { (D) Magdalena Skoczylas }}^{1}$
}

Received: 6 April 2018 / Revised: 29 June 2018 / Accepted: 3 July 2018 / Published online: 18 July 2018

(c) The Author(s) 2018

\begin{abstract}
Amino acids and peptides (di- and tripeptides) as chemically bonded ligands in liquid chromatography were investigated. The comparison between 9 home-made amino acid- and peptide-silica stationary phases in hydrophilic interaction liquid chromatography (HILIC) and reversed-phase liquid chromatography (RP HPLC) systems has been presented. The investigated stationary phases were modified by the following amino acids: phenylalanine, leucine, alanine, glycine, and aspartic acid. Desired interactions were derived from the retention variation between pairs of similar solutes differing with particular structure properties. In the case of HILIC mode, the characterization was performed in terms of the degree of hydrophilicity, selectivity for hydrophilic-hydrophobic compounds, selectivity for the regio and configurational substituents, anion and cation exchange properties, and acidic or basic nature of the stationary phase surface. Under RP HPLC conditions, following features were elucidated: hydrophobicity, hydrophobic selectivity, shape selectivity, hydrogen bonding, electrostatic interactions at $\mathrm{pH}$ values 2.7 and 7.6. The results of the selectivity for partial structural differences were presented as radar-shaped plots and in tabular format. The factor analysis (FA) based on the principal component analysis (PCA) was also used in the stationary phase comparison. The performed research assisted in the evaluation of the relation between the chemical properties of bonded amino acid sequence and their role in the retention mechanism.
\end{abstract}

Keywords RP HPLC $\cdot$ HILIC $\cdot$ Amino acids $\cdot$ Radar plots $\cdot$ Retention mechanism $\cdot$ Column classification

\section{Introduction}

Linear peptides constitute convenient organic components in separation materials due to a wide range of side chain chemistries (linear, branched, or aromatic alkyl groups, thiols, amines, carboxylic acids, etc.) [1]. Recently according to impressive progress in hydrophilic interaction chromatography (HILIC), evaluation of stationary phases with, inter alia, chemically bonded amino acids and peptides could be

Published in Chromatographia's 50th Anniversary

Commemorative Issue.

Electronic supplementary material The online version of this article (https://doi.org/10.1007/s10337-018-3569-2) contains supplementary material, which is available to authorized users.

Bogusław Buszewski

bbusz@umk.pl

1 Chair of Environmental Chemistry and Bioanalytics, Faculty of Chemistry, Nicolaus Copernicus University in Torun, Gagarin 7 St., 87-100 Toruń, Poland observed [2,3]. Depending on the immobilized sequence of amino acids, these materials exhibit diversified application targets.

Grushka and Scott [4] the originators of this type of materials, applied bonded optically active tripeptide stationary phases for the separation of $\mathrm{D}, \mathrm{L}$-amino acids, isomeric dipeptides, and phenyltiohydantoin (PTH)-amino acids derivatives $[4,5]$. Peptide-bonded phases were also an essential component of the internal surface reversed-phase (ISRP) columns introduced by Hagestam and Pinkerton [6]. Peptide-bonded ISRP packings were specifically designed for separation of drugs in blood serum or plasma by direct injection [7]. In the last decade, there have been several investigations of amino acids, peptides, and polypeptides grafted onto silica as stationary phases for liquid chromatography (LC). Amino acids are natural zwitterionic compounds and their immobilization on the silica surface enables the preparation of ion-exchange stationary phases for both HILIC and ion chromatography (IC) systems [8-10]. On the other hand, polypeptides as chemically bonded ligands were evaluated in terms of enantioselectivity [11-14]. Shorter sequences of 
amino acids (i.e. di-, tri-, and tetrapeptides) were also investigated with regard to chemically bonded stationary phases for LC. These materials were evaluated anew by Xue et al. [15] applied in off-line two-dimensional liquid chromatography (2D-RP/RP LC). Further, Ray et al. [16] developed hydrophilic tripeptide-based organosilica hybrid stationary phases dedicated for analysis of bioactive polar compounds under HILIC and RP conditions [16, 17]. Recently, Li et al. [1] have also demonstrated differences between linear and cyclic tetrapeptide-bonded stationary phases [1].

The practitioners and theoreticians of HPLC are interested in the chromatographic evaluation of new and commercial chromatographic packings. The establishment of similarities or dissimilarities between particular stationary phases as well as the description of the retention mechanism induce the validity of such research for both groups [18-22]. To compare the columns used, numerous chromatographic tests were evaluated. The specifics of the evaluated tests for RP-like column were extensively reviewed by Lesselier and West [23]. The concept of the research is based either on the retention factors of the test solutes, or the separation factor between suitably chosen compounds, or on the asymmetry and number of theoretical plates for the chromatographic peaks. Generally, they evaluate a number of stationary phase properties, e.g. hydropathy, shape selectivity, ion-exchange capability, silanol activity, etc. While the idea of such research is largely similar, the performance of column classification is diversified [23, 24]. The accurate comparison of the column properties, without modification of data, is provided by radar plots. Kimata et al. [25] developed one of the first tests for RP-like column that is commonly known as Tanaka's test. The concept was based on differences in selectivities of stationary phases for certain pairs of compounds [25]. The form of radar plots was implemented for HILIC-compatible column by Kawachi et al. [26] and further applied by Dolci [27]. However, this form cannot be used to compare a great number of packings. Another approach comprises statistical methods such as hierarchical cluster analysis (HCA), principal component analysis (PCA) or multiple linear regression (MLR). Lämmerhofer et al. [28] used PCA to compare HILIC chromatographic systems with mixed-mode ion-exchange and reversed-phase systems. They investigated the retention behaviour of xanthins, nucleosides, vitamins, etc. on stationary phases of varied nature under the above systems [28]. Dinh et al. [29] also characterized interactions between a select set of solutes and 22 hydrophilic commercial stationary phases. The phases investigated covered a wide range of surface functional groups including zwitterionic, neutral, cationic, and anionic ones. The PCA approach enables to describe the retention mechanisms on those columns [29]. Chirita et al. [30] proposed a convenient scheme for column selection that applied the analysis of neurotransmitters.
PCA calculations allowed them to find evidence of different separation behavior between the stationary phases, based on the retention data measured for three compound classes: anionic acidic compounds, cationic basic compounds, and zwitterionic amino acids. Despite having evident advantages, statistic methods also reveal some drawbacks. In the case of HCA, dendrograms cannot help in the choice of a column to achieve a given separation. Moreover, the mathematical treatment in PCA reduces the accuracy and the understanding of the classification [23].

Another way to column development according to the predominant retention mechanism is MLR like linear solvation energy relationship (LSER). The measurement of retention factors for a number of solutes, which molecular descriptors are known, in a given chromatographic mode, allows the determination of the factors taking part in the chromatographic retention [23, 31, 32]. Jandera et al. [33] used LSERs to describe retention of phenolic acids and flavone antioxidants on five polar columns under RP HPLC and HILIC. Chirita et al. [34] applied LSER models on zwitterionic stationary phases. They modified the solvation parameter model through the introduction of two additional molecular descriptors to account for ionic interactions with anionic and cationic species. This allows for rationalizing the interactions contributing to retention and separation in the HILIC systems [34]. Further, Schuster and Lindner [24] applied similar methodology for 22 commercially available and home-made stationary phases under HILIC conditions. However, they applied solutes more diverse in their chemical nature, modified mobile phase composition according to the amount of buffer salt and water, and performed all LSERs with D descriptors calculated for $\mathrm{pH} 3$. They highlighted that LSER models reveal limitation in prediction of solute retention if not operated under a predominated HILIC partition mechanism. This outcome can be attributed to unclear contributions of electrostatic interactions in the considered model [24].

The side chain of immobilized amino acids sequence has the major effect on the absolute properties of the amino acidand peptide-silica stationary phases. In many cases, this type of materials reveals a mixed RP/HILIC mechanism. Thus, in the case of such stationary phases both the described modes should be considered. For this reason, the aim of the present study was to evaluate the retention behavior of hydrophilic and hydrophobic model solutes on 9 home-made stationary phases with immobilized amino acids and peptides. The investigated stationary phases comprise chemically bonded amino acids of different types [glycine (Gly), alanine (Ala), phenylalanine (Phe), leucine (Leu), and aspartic acid (Asp)] and chain lengths (amino acid, di- and tripeptides). The preparation and characterization of the tested stationary phases were presented elsewhere $[35,36]$. To elucidate selectivity and interaction modes of the materials 
of interest Kawachi et al. [26] test preferred for HILIC-compatible materials and Tanaka`s test [25] dedicated for RPcompatible column were performed. The following features were designated for the HILIC test: hydrophilicity, selectivity for hydrophilic-hydrophobic compounds, selectivity for the regio- and configurational substituents, anion and cation exchange properties, and acidic or basic nature of the stationary phase surface; as for the RP test these were: hydrophobicity, hydrophobic selectivity, shape selectivity, hydrogen bonding, electrostatic interactions at $\mathrm{pH}$ values 2.7 and 7.6. The obtained results of the selectivity for partial structural differences were presented as radar-shaped plots and in tabular format. The factor analysis (FA) based on the principal component analysis (PCA) was also used in the stationary phase comparison. The applied column characterization methodology allowed for general classification of the tested stationary phases according to their chromatographic properties. The tested columns were also compared with regard to carbohydrates and polyols separation under HILIC conditions.

\section{Experimental}

\section{Chemicals}

HPLC-grade acetonitrile, methanol, ammonium acetate $\left(\mathrm{NH}_{4} \mathrm{Ac}\right)$, potassium phosphate monobasic $\left(\mathrm{KH}_{2} \mathrm{PO}_{4}\right)$, phosphoric acid, and potassium hydroxide were purchased from Sigma-Aldrich, St. Louis, MO, USA. HPLC-grade acetic acid was obtained from J.T. Baker, Deventer, The Netherlands. Water was purified using the Milli-Q system (Millipore, El Paso, TX, USA) in our laboratory. $n$-Pentylbenzene was purchased from Alfa Aesar, Kandel, Germany. The other test analytes as well as carbohydrates standards were supplied by Sigma-Aldrich, St. Louis, MO, USA.

\section{Instrumentation}

Chromatographic experiments were performed on the following Shimadzu LC systems: (1) Shimadzu Prominence LC (Kyoto, Japan) equipped with quaternary gradient pump (LC-20AD), an autosampler (SIL-20A), a diode array detector (SPD-M20A), and a column thermostat (CTO-10AS). (2) Shimadzu UHPLC Nexera (Kyoto, Japan) consisting of a binary gradient pump (LC-30AD), an autosampler (SIL30AC), a diode array detector (SPD-M20A), and a column thermostat (CTO-30A). The carbohydrates separations were performed on the Shimadzu Prominence LC (Kyoto, Japan) equipped with quaternary gradient pump (LC-20AD), an autosampler (SIL-20A), a column thermostat (CTO-10AS), and low temperature-evaporative light scattering detector (ELSD-LT II, Shimadzu, Kyoto, Japan). Instrument control, data acquisition, and processing were performed with LabSolutions software for HPLC.

\section{Chromatographic Tests}

The chromatographic measurements were carried out on nine different home-made columns. The structures of chemically bonded ligands are presented in Fig. 1. The physicochemical properties of the tested stationary phases are listed in Table 1 . The following amino acid- and peptide-silica stationary phases were employed: amino-(Gly $)_{1}$, amino(Gly) ${ }_{3}$, amino-(Asp) $)_{1}$, amino-(Ala $)_{2}$, amino-(Leu $)_{1}$, amino(Leu $)_{2}$, amino-(Leu $)_{3}$, amino-(Phe $)_{1}$, and amino-(Phe $)_{2}$ $(5 \mu \mathrm{m}, 125 \mathrm{~mm} \times 4.6 \mathrm{~mm})$. The stationary phase chemically modified with aminopropyl ligand (silica-Amino; $5 \mu \mathrm{m}$, $125 \mathrm{~mm} \times 4.6 \mathrm{~mm}, 2.84 \mu \mathrm{mol} / \mathrm{m}^{2}$ ) [37] and commercial column (ObeliscN, $5 \mu \mathrm{m}, 150 \mathrm{~mm} \times 4.6 \mathrm{~mm}$, SIELC Technologies, Wheeling, IL, USA) were also used in the carbohydrates and polyols separation.

Working solutions comprised selected pairs of compounds as well as toluene (HILIC) and thiourea (RP HPLC) as void volume markers. The composition of particular mixtures, the structure of solutes, the investigated selectivity, and the mobile phase compositions are presented in Table 2. In the case of RP test, the modification of experimental conditions was performed and described in Online Resource.

At least 15 column volumes of the appropriate mobile phase were flushed through all the columns prior to the chromatographic evaluation. Flow rate and injection volume of test mixture were scaled for $0.5 \mathrm{~mL} \mathrm{~min}^{-1}$ and $1 \mu \mathrm{L}$, respectively. Throughout the experiments, the columns were maintained at $30^{\circ} \mathrm{C}$. The detection was performed at $254 \mathrm{~nm}$. The retention data was determined as the average of three replicate injections.

\section{The Chemometric Calculations}

The statistic calculations were performed by Statistica 7.1 DataMiner software (Statsoft, Cracow, Poland) running on the Windows platform. The factor analysis (FA) based on principal component analysis (PCA) with normalized Varimax rotation were applied to classify the columns according to the measured features (different types of selectivities).

\section{Results and Discussion}

\section{Hydrophobic and Hydrophilic Interactions}

The retention coefficients and selectivity factors of the separations governed by hydrophobic and hydrophilic interactions are presented in Table 3. The separation provided by a methylene group reveals poor selectivity 
Fig. 1 Structures of the amino acid- and peptide-silica stationary phases

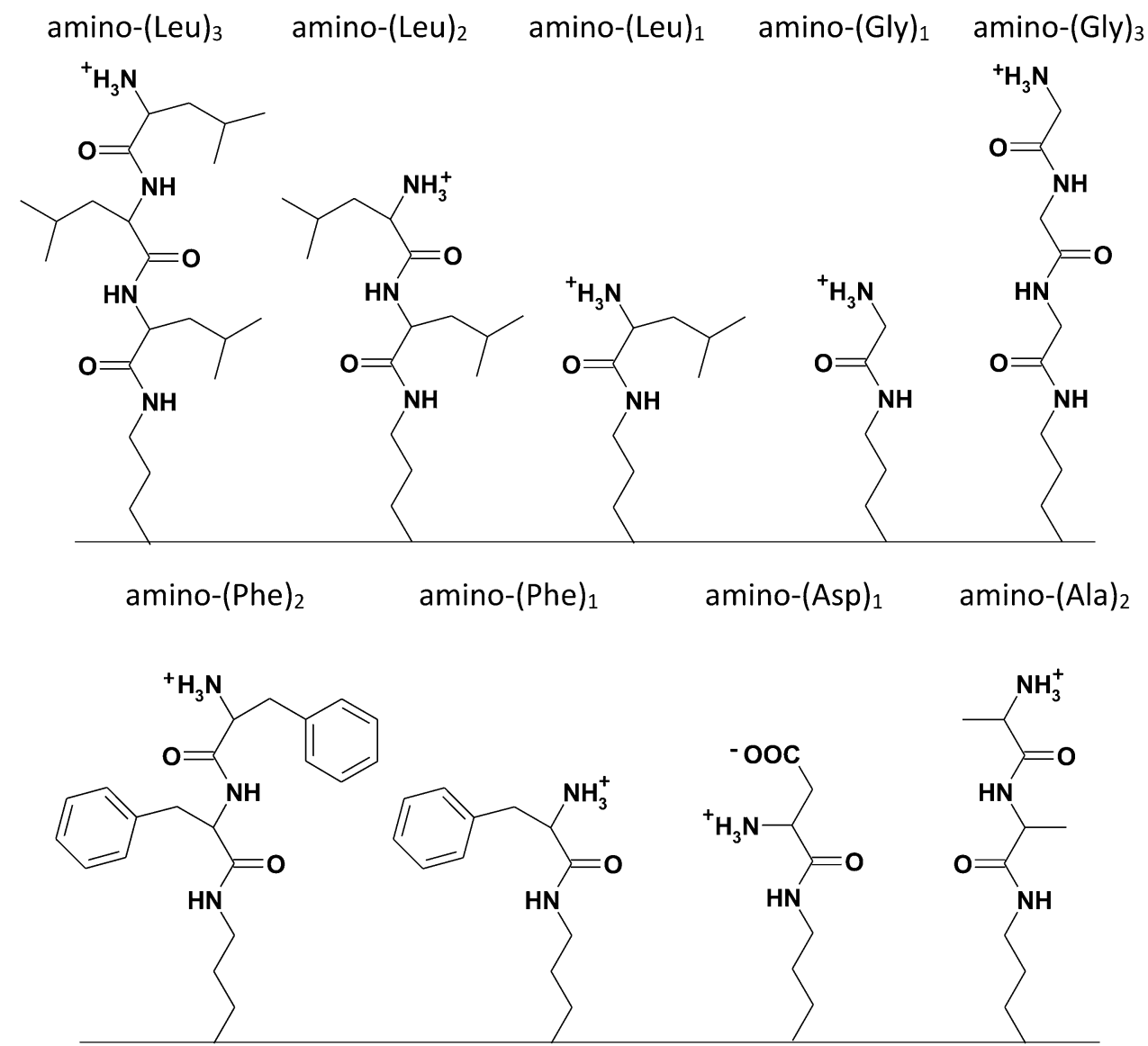

Table 1 Coverage density of the tested stationary phases

\begin{tabular}{lllll}
\hline Column & Bonded moiety & $\begin{array}{l}\text { Carbon content } \\
(\%)\end{array}$ & $\begin{array}{l}\text { The primary coverage density of ami- } \\
\text { nopropyl groups }\left(\mu \mathrm{mol} \mathrm{m}^{-2}\right)\end{array}$ & $\begin{array}{l}\text { The amount of bonded } \\
\text { amino acids ligands }(\mu \mathrm{mol} \\
\left.\mathrm{m}^{-2}\right)\end{array}$ \\
\hline Amino-(Gly) $)_{3}$ & Tripeptide of glycine & 5.29 & 3.00 & 3.13 \\
Amino-(Gly) $)_{1}$ & Glycine & 4.61 & 3.24 & 1.67 \\
Amino-(Asp) $)_{1}$ & Aspartic acid & 6.61 & 2.95 & 2.59 \\
Amino-(Ala) $)_{2}$ & Dipeptide of alanine & 6.15 & 3.00 & 2.90 \\
Amino-(Leu) $)_{3}$ & Tripeptide of leucine & 12.13 & 3.24 & 4.14 \\
Amino-(Leu) $)_{2}$ & Dipeptide of leucine & 10.37 & 3.24 & 3.33 \\
Amino-(Leu) $)_{1}$ & Leucine & 7.39 & 3.24 & 1.92 \\
Amino-(Phe $)_{2}$ & Dipeptide of phenylalanine & 11.57 & 2.94 & 2.88 \\
Amino-(Phe $)_{1}$ & Phenylalanine & 8.15 & 2.95 & 1.63
\end{tabular}

for all the tested columns. The discrimination between uridine and $2^{\prime}$-deoxyuridine under the test conditions was higher than the separation governed by hydrophobic interactions. In both separation cases, materials with chemically bonded hydrophilic amino acids and peptides exhibit higher selectivity. As a consequence, the statement that this group of materials may be dedicated to HILIC mode has been explicated. Among this polar group of materials, amino-(Gly) ${ }_{3} \mathrm{SP}$ (material with the longest sequence of hydrophilic amino acid) and amino-(Asp) $)_{1} \mathrm{SP}$ (packing with a single layer of polar molecule) comprise the most retentive materials. This contradiction in terms of length of bonded peptide chain shows that the properties and character of bonded amino acids influence the hydrophilic interactions but more than their number in a peptide chain. On the other hand, the immobilization 
Table 2 Operation parameters of chromatographic tests and properties of the tested compounds

\begin{tabular}{|c|c|c|c|c|c|c|}
\hline Property & Sign & Tested solutes & Molecular stucture & pKa & $\begin{array}{l}\log D \\
\log P *\end{array}$ & $\begin{array}{l}\text { Mobile phase } \\
\text { composition }\end{array}$ \\
\hline \multicolumn{7}{|c|}{ HILIC mode } \\
\hline $\begin{array}{l}\text { Hydrophobic } \\
\text { interactions }\end{array}$ & $\alpha\left(\mathrm{CH}_{2}\right)$ & $\begin{array}{l}\text { Uridine - } \\
\text { 5-methyluridine }\end{array}$ & & $\begin{array}{l}12.6 \\
12.0\end{array}$ & $\begin{array}{l}-1.58 \\
-1.02\end{array}$ & \multirow{7}{*}{$\begin{array}{c}\mathrm{ACN} / 20 \mathrm{mM} \\
\mathrm{NH}_{4} \mathrm{Ac} \\
\mathrm{pH}=4.7 \\
\left(90 / 10_{\mathrm{v} / \mathrm{v}}\right)\end{array}$} \\
\hline $\begin{array}{l}\text { Hydrophilic } \\
\text { interactions }\end{array}$ & $\alpha(\mathrm{OH})$ & $\begin{array}{c}\text { Uridine - } \\
\text { 2-deoxyuridine }\end{array}$ & & $\begin{array}{l}12.6 \\
13.9\end{array}$ & $\begin{array}{l}-1.58 \\
-1.26\end{array}$ & \\
\hline $\begin{array}{l}\text { Configurational } \\
\text { isomers selectivity }\end{array}$ & $\alpha(\mathrm{V} / \mathrm{A})$ & $\begin{array}{l}\text { Vidarabine - } \\
\text { adenosine }\end{array}$ & & $\begin{array}{l}13.9 \\
13.9\end{array}$ & $\begin{array}{l}-1.02 \\
-1.03\end{array}$ & \\
\hline $\begin{array}{l}\text { Regioisomers } \\
\text { selectivity }\end{array}$ & $\alpha(2 d G / 3 d G)$ & $\begin{array}{l}\text { 2'-deoxyguanosine - } \\
\text { 3`-deoxyguanosine }\end{array}$ & & $\begin{array}{l}13.5 \\
13.5\end{array}$ & $\begin{array}{l}-1.14 \\
-1.14\end{array}$ & \\
\hline $\begin{array}{l}\text { Anion exchange } \\
\text { selectivity }\end{array}$ & $\alpha(A X)$ & $\begin{array}{c}\text { Sodium p-toluenesulfonate } \\
- \text { uracil }\end{array}$ & & $\begin{array}{c}-12.8 \\
13.8\end{array}$ & $\begin{array}{r}0.88 \\
-1.08\end{array}$ & \\
\hline $\begin{array}{l}\text { Cation exchange } \\
\text { selectivity }\end{array}$ & $\alpha(C X)$ & $\begin{array}{c}\mathrm{N}, \mathrm{N}, \mathrm{N}- \\
\text { trimethylphenylammonium } \\
\text { chloride - uracil }\end{array}$ & & $\begin{array}{c}- \\
13.8\end{array}$ & $\begin{array}{l}-2.31 \\
-1.08\end{array}$ & \\
\hline $\begin{array}{l}\text { Acidic-basic nature of } \\
\text { stationary phase }\end{array}$ & $\alpha(\mathrm{Tb} / \mathrm{Tp})$ & $\begin{array}{l}\text { Theobromine - } \\
\text { theophylline }\end{array}$ & & $\begin{array}{l}10 \\
8.6\end{array}$ & $\begin{array}{l}-1.06 \\
-2.51\end{array}$ & \\
\hline \multicolumn{7}{|c|}{ RP mode } \\
\hline Hydrophobicity & $\alpha\left(\mathrm{CH}_{2}\right)$ & $\begin{array}{l}\mathrm{n} \text {-Pentyl- and } \\
\text { butylbenzene }\end{array}$ & & - & $\begin{array}{l}5.0 \\
4.4\end{array}$ & \multirow{2}{*}{$\begin{array}{l}\mathrm{ACN} / \mathrm{H}_{2} \mathrm{O} \\
\left(30 / 70_{\mathrm{v} / \mathrm{v}}\right)\end{array}$} \\
\hline Steric selectivity & $\alpha(T / 0)$ & $\begin{array}{l}\text { Triphenylene - } \\
\text { o-terphenyl }\end{array}$ & & - & $\begin{array}{l}4.9 \\
5.5\end{array}$ & \\
\hline $\begin{array}{l}\text { Hydrogen bonding } \\
\text { capacity }\end{array}$ & $\alpha(C / P)$ & $\begin{array}{l}\text { Caffeine - } \\
\text { phenol }\end{array}$ & & $\begin{array}{l}10.4 \\
9.99\end{array}$ & $\begin{array}{l}-0.1 \\
1.46\end{array}$ & $\begin{array}{l}\mathrm{MeOH} / \mathrm{H}_{2} \mathrm{O} \\
\left(30 / 70_{\mathrm{v} / \mathrm{v}}\right)\end{array}$ \\
\hline $\begin{array}{c}\text { Ion-exchange capacity } \\
\text { at } \mathrm{pH}>7\end{array}$ & $\alpha(B / P)_{7.6}$ & \multirow{2}{*}{$\begin{array}{l}\text { Benzylamine - } \\
\text { phenol }\end{array}$} & & \multirow{2}{*}{$\begin{array}{l}9.34 \\
9.99\end{array}$} & \multirow{2}{*}{$\begin{array}{c}1.1 \\
1.46\end{array}$} & $\begin{array}{c}\mathrm{MeOH} / 20 \\
\mathrm{mM} \mathrm{KH}_{2} \mathrm{PO}_{4} \\
\mathrm{pH}=7.6 \\
\left(30 / 70_{\mathrm{v} / \mathrm{v}}\right)\end{array}$ \\
\hline $\begin{array}{c}\text { Ion-exchange capacity } \\
\text { at } \mathrm{pH}<3\end{array}$ & $\alpha(B / P)_{2.7}$ & & & & & $\begin{array}{c}\mathrm{MeOH} / 20 \\
\mathrm{mM} \mathrm{KH}_{2} \mathrm{PO}_{4} \\
\mathrm{pH}=2.7 \\
\left(30 / 70_{\mathrm{v} / \mathrm{v}}\right)\end{array}$ \\
\hline
\end{tabular}

*Value presented in this column correspond to $\log D$ of particular solutes in the case of HILIC test, while in RP conditions $\log P$ values were provided 
Table 3 Separation parameters for hydrophobic and hydrophilic interactions

\begin{tabular}{lllllll}
\hline Column & $k(\mathrm{U})$ & $k(5 \mathrm{MU})$ & $\alpha(\mathrm{CH})_{2}$ & $k(\mathrm{U})$ & $k(2 \mathrm{dU})$ & $\alpha(\mathrm{OH})$ \\
\hline Amino-(Gly) & 1.78 & 1.51 & 1.18 & 1.77 & 1.19 & 1.49 \\
Amino-(Gly) $_{1}$ & 1.64 & 1.40 & 1.18 & 1.66 & 1.12 & 1.48 \\
Amino-(Asp) $_{1}$ & 1.70 & 1.46 & 1.17 & 1.71 & 1.11 & 1.54 \\
Amino-(Ala) $_{2}$ & 1.72 & 1.44 & 1.19 & 1.73 & 1.10 & 1.58 \\
Amino-(Leu) $_{3}$ & 0.43 & 0.40 & 1.08 & 0.44 & 0.35 & 1.26 \\
Amino-(Leu) $_{2}$ & 0.40 & 0.37 & 1.08 & 0.40 & 0.31 & 1.29 \\
Amino-(Leu) $_{1}$ & 0.62 & 0.56 & 1.00 & 0.62 & 0.48 & 1.34 \\
Amino-(Phe) & 0.31 & 0.31 & 1.10 & 0.31 & 0.23 & 1.30 \\
Amino-(Phe) & 0.73 & 0.66 & 1.11 & 0.74 & 0.58 & 1.27 \\
\hline
\end{tabular}

$U$ uridine, $5 M U$ 5-methyluridine, $2 d U 2^{\prime}$-deoxyuridine of hydrophobic peptides onto silica surface implies lower selectivity for the tested compounds. The amino acid sequence with branched hydrophobic side chains may cause hampered penetration of hydrophilic solutes towards incorporated polar groups $(\mathrm{CO}, \mathrm{NH})$.

From Table 3 it can be also summarized that amino(Leu $)_{x}$ and amino-(Phe $)_{x}$ showed similar selectivity for $\alpha\left(\mathrm{CH}_{2}\right)$. These results proved that the difference in the type and the length of hydrophobic side chain of bonded amino acids and peptides had little effect on hydrophobic interactions under HILIC conditions. Besides, the $\alpha(\mathrm{OH})$ is similar for columns with immobilized leucine, and some correlations may be found. The decrease of the $\alpha(\mathrm{OH})$ for amino-(Leu $)_{1}$, amino-(Leu $)_{2}$, and amino-(Leu $)_{3}$ order was observed. The increase of hydrophobic character of the stationary phase surface, due to the immobilization of longer hydrophobic peptide chain, implies the reduction of selectivity governed by polar hydroxy group. Overall, the hydrophilic interactions provided higher specificity, which was demonstrated by a more extended variation of $\alpha(\mathrm{OH})$ than $\alpha\left(\mathrm{CH}_{2}\right)$. This was an evident consequence of the applied HILIC conditions.

\section{Isomeric Selectivity}

As listed in Table 4, the amino acid- and peptide-silica stationary phases tended to give greater $\alpha$ (V/A) in comparison with $\alpha(2 \mathrm{dG} / 3 \mathrm{dG})$. Thus, the discrimination degree was higher for configurational isomers in comparison with regioisomers. Among the tested columns, the amino-(Ala $)_{2}$ SP provided the best selectivity $[\alpha(\mathrm{OH})=1.29]$ for configurational isomers. The other materials possessed, however, similar selectivity with regard to amino-(Ala $)_{2}$ material. According to Table 4, it can be emphasized that materials with chemically bonded hydrophobic amino acid sequences exhibit slightly lower $\alpha(\mathrm{V} / \mathrm{A})$ with regard to the hydrophilic group of packings. The nature of chemically bonded ligands impedes univocal HILIC retention due to the hydrophobic moieties. Overall, the amino acids and peptides (with hydrophilic side chains) as bonded functionalities may constitute applicative ligands for improving the separation of nucleosides, nucleic bases, and saccharides. These possibilities were reported earlier elsewhere [35].

The selectivity of regioisomers was similar for all the tested materials and did not exceed the value of 1.08 (Table 4). The comparable data were observed by Kawachi et al. [26] and Dolci [27] for the commercially available
Table 4 The chromatographic factors of stereoselectivity tests

\begin{tabular}{|c|c|c|c|c|c|c|}
\hline \multirow[t]{2}{*}{ Column } & \multicolumn{3}{|c|}{ Configurational isomerism } & \multicolumn{3}{|c|}{ Regioisomerism } \\
\hline & $k(\mathrm{~V})$ & $k(\mathrm{~A})$ & $\alpha(\mathrm{V} / \mathrm{A})$ & $k(2 \mathrm{dG})$ & $k(3 \mathrm{dG})$ & $\alpha(2 \mathrm{dG} / 3 \mathrm{dG})$ \\
\hline Amino-(Gly $)_{3}$ & 2.86 & 2.28 & 1.26 & 4.84 & 4.55 & 1.06 \\
\hline Amino-(Gly $)_{1}$ & 2.75 & 2.19 & 1.26 & 4.58 & 4.31 & 1.06 \\
\hline Amino-(Asp) $)_{1}$ & 2.67 & 2.17 & 1.23 & 4.73 & 4.41 & 1.07 \\
\hline Amino-(Ala) ${ }_{2}$ & 1.90 & 2.45 & 1.29 & 4.21 & 4.21 & 1.00 \\
\hline Amino-(Leu $)_{3}$ & 0.96 & 0.76 & 1.25 & 1.71 & 1.71 & 1.00 \\
\hline Amino-(Leu $)_{2}$ & 0.83 & 0.67 & 1.22 & 1.43 & 1.43 & 1.00 \\
\hline Amino-(Leu $)_{1}$ & 1.21 & 1.00 & 1.21 & 1.94 & 1.85 & 1.05 \\
\hline Amino-(Phe $)_{2}$ & 0.66 & 0.58 & 1.14 & 1.34 & 1.34 & 1.00 \\
\hline Amino-(Phe $)_{1}$ & 1.52 & 1.28 & 1.18 & 2.30 & 2.13 & 1.08 \\
\hline
\end{tabular}

$V$ vidarabine, $A$ adenosine, $2 d G 2^{\prime}$-deoxyguanosine, $3 d G 3^{\prime}$-deoxyguanosine 
HILIC columns. Among the tested columns, amino-(Gly) $)_{x}$, amino-(Asp) $)_{1}$, and amino-(Phe) $)_{1}$ revealed the highest selectivity values equal around 1.1. The regioisomers coeluted on the other amino acid- and peptide-silica stationary phases. Thus, the amino acid- and peptide-silica stationary phases exhibit higher specificity for conformers of saccharides, whereas the position of the desired functionalities was less recognized.

\section{Ion-Exchange Interactions}

The immobilization of amino acids and peptides onto silica surface generates the anion exchange (AX) properties of the prepared materials. The primary amino groups localized at the end of the peptide sequences are protonated in experimental conditions. Moreover, the specific side chain of aspartic acid may act as cation-exchanger functionality (CX), due to the presence of additional carboxyl group. The unbonded amino groups and accessible silanols, particularly in the case of materials with a single layer of amino acids, would also have impact on the ion-exchange interactions. Thus, the investigation of this type of phenomena constitutes an inherent test of column classification.

According to Table 5, the anion-exchange ability was observed for all the stationary phases except the amino(Asp) $)_{1}$. As regards, materials with immobilized aspartic acid, sodium $p$-toluenesulfonate (SPTS) eluted earlier than uracil. This may arise from the electrostatic repulsion due to the presence of partially ionized carboxyl group in the side chain of amino acid. The strongest anion interactions $(\alpha(\mathrm{AX})=6.86)$ are exhibited by stationary phase with immobilized dipeptide of alanine-amino-(Ala) ${ }_{2}$ SP. The $\alpha(\mathrm{AX})$ values were similar for amino-(Leu) $)_{x}$ stationary phases. This proved that the length of amino acid sequences does not influence significantly the anion-exchange properties of the tested stationary phases. Considering the structure of a

Table 5 Retention factors and selectivities of ionic compounds

\begin{tabular}{lllll}
\hline Column & $k$ (SPTS) & $k$ (TMPAC) & $\begin{array}{l}\alpha \text { (AX) } \\
\alpha \text { (SPTS/Ur) }\end{array}$ & $\begin{array}{l}\alpha(\mathrm{CX}) \\
\alpha \text { (TMPAC/ } \\
\mathrm{Ur})\end{array}$ \\
\hline Amino-(Gly) $_{3}$ & 2.27 & 1.65 & 2.64 & 1.92 \\
Amino-(Gly) $_{1}$ & 3.38 & 1.18 & 4.14 & 1.45 \\
Amino-(Asp) $_{1}$ & 0.67 & 3.74 & 0.82 & 4.55 \\
Amino-(Ala) $_{2}$ & 5.59 & 0.16 & 6.86 & 0.20 \\
Amino-(Leu) $_{3}$ & 1.67 & 1.00 & 3.99 & 1.00 \\
Amino-(Leu) $_{2}$ & 1.46 & 0.43 & 4.41 & 1.32 \\
Amino-(Leu) & 1.66 & 1.02 & 4.00 & 2.45 \\
Amino-(Phe) & 0.69 & 0.60 & 2.51 & 2.19 \\
Amino-(Phe) & 0.82 & 3.10 & 1.75 & 6.71 \\
\hline
\end{tabular}

SPTS sodium $p$-toluenesulfonate, TMPAC N,N,N-trimethylphenylammonium chloride, $U r$ uracil chemically bonded ligand, it is evident that the AX functionality (the primary amino group) is localized at the end of the peptide chain. Thus, the AX capability results from the appearance of amino group, whereas the length of bonded ligand is negligible.

In the case of the tested stationary phases, the cationexchange character may arise only from the presence of residual silanols. The $\mathrm{p} K_{\mathrm{a}}$ of around 4.7 for silanol moieties implies their partial deprotonation under experimental conditions. Thus, the $\mathrm{SiO}^{-}$groups act as a cation-exchange functionality and influence the retention in HILIC mode. According to Table 5, the zwitterionic phase, amino-(Asp) exhibited appreciable $\mathrm{CX}$ character, while $\mathrm{AX}$ interactions were significantly reduced. Thus, the amino-(Asp) $)_{1}$ showed strong CX interactions due to the carboxyl group in the phase. Similar character was displayed by the commercially available zwitterionic stationary phase ZIC-HILIC that showed considerable $\mathrm{CX}$ interactions due to the presence of sulfo group [26]. Among the stationary phases tested, amino-(Phe $)_{1}$ also demonstrates significant cation-exchange interactions with $\alpha(\mathrm{CX})$ equal 6.71 (Table 5). The immobilization of a single layer of amino acid to a lesser extent shields the available residual silanols. This column also possessed the lowest coverage density of bonded amino acid reported in the previous work [36]. The steric hindrance between phenylalanine molecules caused less efficient derivatization, and thus more exposed silanol groups of silica support. Other stationary phases exhibited much smaller or no [amino-(Ala) $)_{2}$ SP] CX character and consequently its lower contribution for the retention under test conditions.

\section{Acidic-Neutral-Basic Nature of the Stationary Phase Surface}

The evaluation of stationary phases with, inter alia, HILIC application should include the description of acidic and basic properties of the adsorbent surface. This is a consequence of the main purpose of HILIC mode - the separation of highly hydrophilic, ionizable compounds. Therefore, the separation of 1,3-dimethylxanthines [theobromine $(\mathrm{Tb})$ and theophylline (Tp)] was performed. The parameter $\alpha(\mathrm{Tb} / \mathrm{Tp})$ demonstrates the $\mathrm{pH}$ on the surface of the stationary phase. The $\alpha(\mathrm{Tb} / \mathrm{Tp})<1$ corresponds to basic stationary phases; $\alpha$ $(\mathrm{Tb} / \mathrm{Tp})=1$ is attributed to the neutral nature of materials; and acidic stationary phases possessed $\alpha(\mathrm{Tb} / \mathrm{Tp})>1$ [28]. These correlations are connected with the properties of the tested analytes due to the stronger basic character of theobromine in comparison with theophylline $\left(\mathrm{p} K_{\mathrm{a}}\right.$ theophylline $=8.6$; $\left.\mathrm{p} K_{\text {a theobromine }}=10\right)$ [38].

Based on the $\alpha(\mathrm{Tb} / \mathrm{Tp})$ parameter, the column classification was performed and reported in Table 6. The coelution of theobromine and theophylline was observed on 
Table 6 Classification of the stationary phases according to theirs surface nature

\begin{tabular}{lllll}
\hline Column name & $k(\mathrm{~Tb})$ & $k(\mathrm{Tp})$ & $\alpha(\mathrm{Tb} / \mathrm{Tp})$ & $\begin{array}{l}\mathrm{pH} \text { conditions of } \\
\text { stationary phase }\end{array}$ \\
\hline Amino-(Gly) $_{3}$ & 0.66 & 0.66 & 1.00 & Neutral \\
Amino-(Asp) $_{1}$ & 0.61 & 0.61 & 1.00 & \\
Amino-(Leu) $_{3}$ & 0.24 & 0.37 & 0.65 & Basic \\
Amino-(Leu) $_{2}$ & 0.22 & 0.35 & 0.62 & \\
Amino-(Leu) $_{1}$ & 0.35 & 0.49 & 0.70 & \\
Amino-(Phe) $_{2}$ & 0.32 & 0.44 & 0.73 & \\
Amino-(Phe) & 0.50 & 0.59 & 0.86 & \\
Amino-(Gly) & 0.58 & 0.85 & 0.85 & \\
Amino-(Ala) & 0.46 & 0.56 & 0.82 & \\
\hline
\end{tabular}

$T b$ theobromine, $T p$ theophylline

amino-(Gly) ${ }_{3}$, amino-(Asp) $)_{1}$, while the other materials stronger retained theophylline than theobromine. Thus, the investigated columns may be divided into two groups; one discriminates the basic nature of solutes while the other do not show any selectivities for xanthin derivatives. In the case of basic columns, such as amino-(Phe $)_{x}$, amino-(Leu $)_{x}$, amino-(Gly) $)_{1}$, and amino-(Ala $)_{2}$ the $\alpha(\mathrm{Tb} /$ $\mathrm{Tp})$ value was smaller than 1.0. The basic nature of the tested materials is in agreement with the proven basic character of conventional amino-based material [26]. On the other hand, amino-(Gly) $)_{3}$ and amino-(Asp) $)_{1}$ represent neutral materials in terms of their functionality due to the $\alpha(\mathrm{Tb} / \mathrm{Tp})=1.0$. Thus, the observed results suggest that the immobilization of hydrophilic amino acids and peptides onto modified silica surface imparts the neutralization of the original amino-based material. The reason of such neutralization may be the creation of amide group as a result of amino acid immobilization. The compilation of acidic nature of amide materials with basic character of amino-based columns may cause alignment of final material properties. Moreover, the observed relations are in compliance with results reported by Kawachi et al. [26]. As result of this work, it was shown that stationary phases with hydroxy groups that imply hydrophilic properties did not discriminate among xanthin derivatives. One of those materials was PolyHYDROXYETHYL A which represents commercially available peptide-based column. It may be concluded that peptide-based materials with hydrophilic amino acids will be characterized by neutral nature of chemically bonded functionalities. The zwitterionic phases exhibit dual nature of the surface with relation to the ligand loading. This type of materials demonstrates acidic or neutral character of bonded functionalities [29]. In the case of monomerically functionalized materials, which include the tested amino-(Asp) $)_{1}$ phase, the neutral nature is observed.

\section{The Comparison of the Investigated Characteristics}

\section{Radar Plots}

The comparison of the overall investigated characteristics of the amino acid- and peptide-silica stationary phases was performed in a pictorial form. Radar shaped graphs allowed for the presentation of multidimensional data in a two-dimensional conformation. Figure $2 \mathrm{a}, \mathrm{b}$ presents the resultant plots for all the tested columns. A specific axis represents individual parameters investigated during this study. The retention factor of uridine $k(\mathrm{U})$ localized at the top of radar plots demonstrates the relation between surface nature of chemically bonded ligands and its influence on the overall retention.

The preferential adsorption of water onto stationary phase surface and the degree of this phenomenon should be also considered as a consequence of HILIC conditions [36]. Among the materials tested, amino-(Gly) $)_{3}$, amino-(Asp) ${ }_{1}$, and amino-(Ala) $)_{2}$ SPs represent the most retentive stationary phases and thus the most hydrophilic materials (Fig. 2). This is in compliance with the previous study that showed the highest excess adsorption of water on those stationary phase surfaces [36]. On the other hand, the materials with chemically bonded hydrophobic amino acids possessed considerably lower $k(\mathrm{U})$ in comparison with the other tested materials. This reflects the impact of hydrophobic side chains of bonded amino acids on the retention mechanism of hydrophilic solutes.

The selectivity of methylene $\alpha\left(\mathrm{CH}_{2}\right)$ and hydroxy group $\alpha(\mathrm{OH})$ tends to give a positive correlation for all the tested columns. However, amino-(Asp) ${ }_{1}$, amino-(Gly) ${ }_{x}$, and amino$(\mathrm{Ala})_{2}$ demonstrate a flat part in the described region of the plotted line, which indicates the prevalence of hydrophilic interactions over hydrophobic phenomena. In other cases, this relation is comparable. Therefore, the domination of hydrophilic interactions or similar contribution of hydrophilic and -phobic phenomena for the tested materials enable their tentative classification for HILIC and mixed-mode applications, respectively. The discrimination of configurational isomers $\alpha(\mathrm{V} / \mathrm{A})$ was comparable for all the investigated stationary phases, while the regioisomers $\alpha(2 \mathrm{dG} / 3 \mathrm{dG})$ were slightly distinguished by materials with immobilized hydrophilic amino acids and peptides. The degree of ionexchange interactions had an imperative influence on the shape of the graphs. According to Fig. 2, amino-(Phe) ${ }_{1}$ and amino-(Asp) ${ }_{1}$ SPs exhibited extremely high cation-exchange capability. In the case of amino-(Asp), the CX character was related to the presence of carboxyl group in the side chain of such amino acid, while in other tested materials the 


\section{amino-(Phe) ${ }_{2}$}

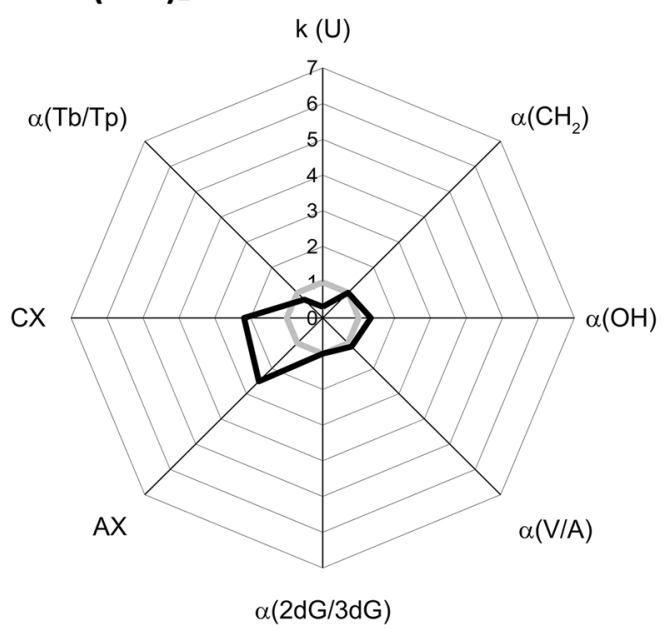

amino-(Leu) 3

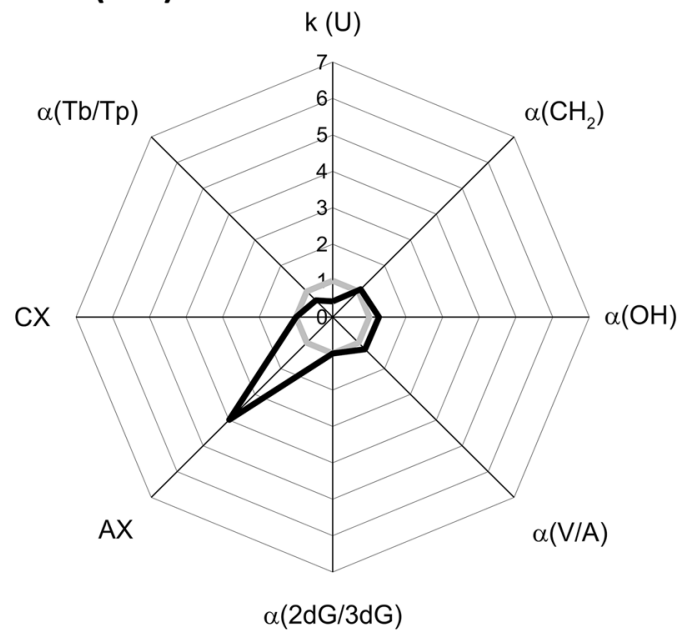

amino-(Leu) 1

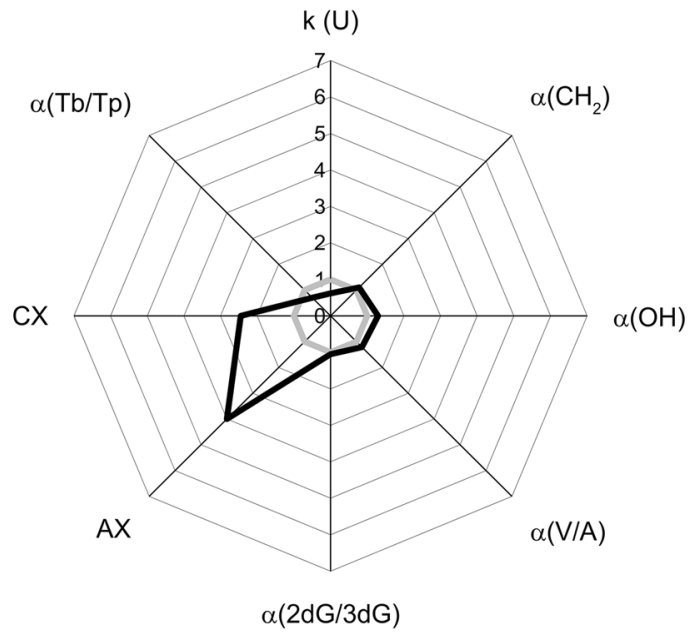

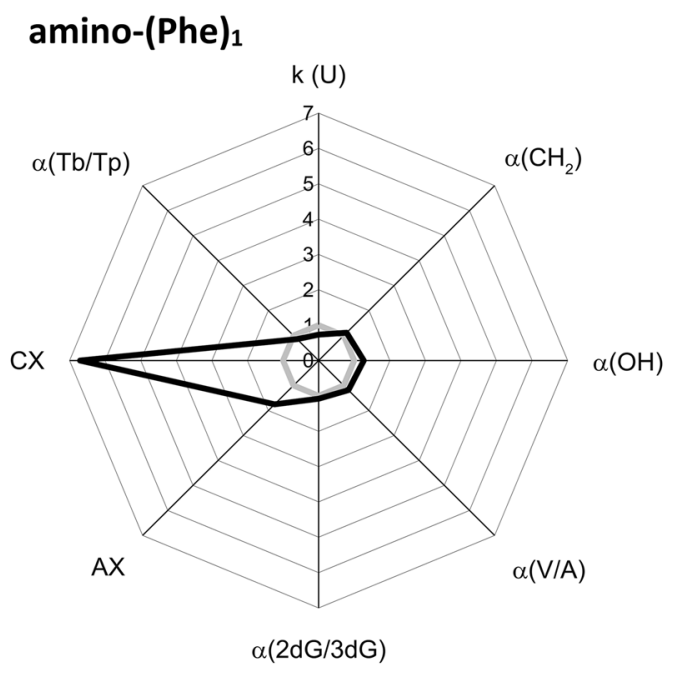

amino-(Leu) 2

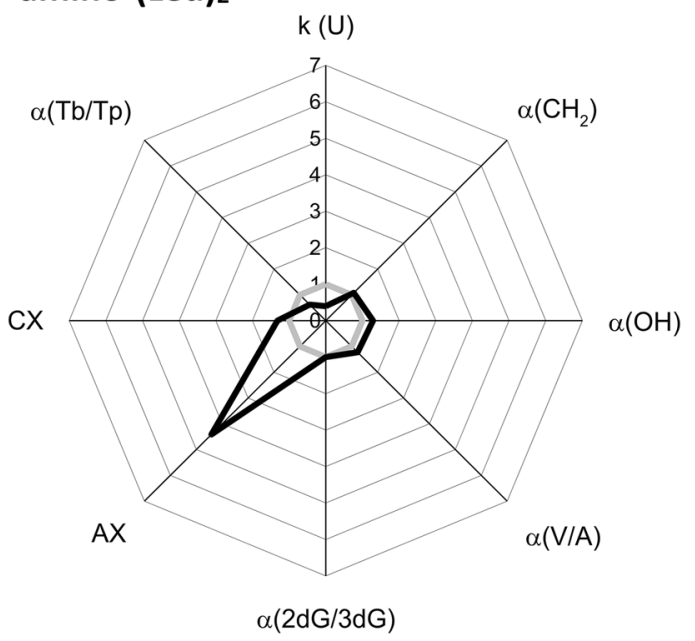

amino-(Ala) 2

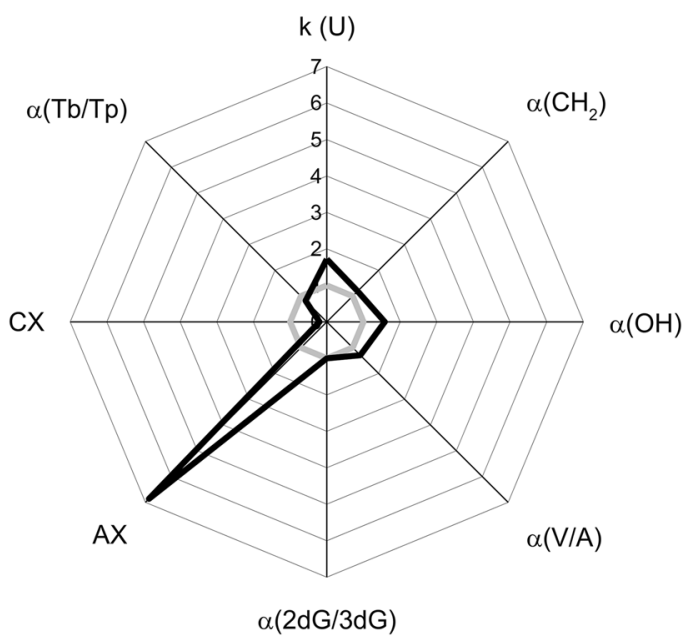

Fig. 2 a, b Radar plots of characterization data - the comparison of the investigated stationary phases 

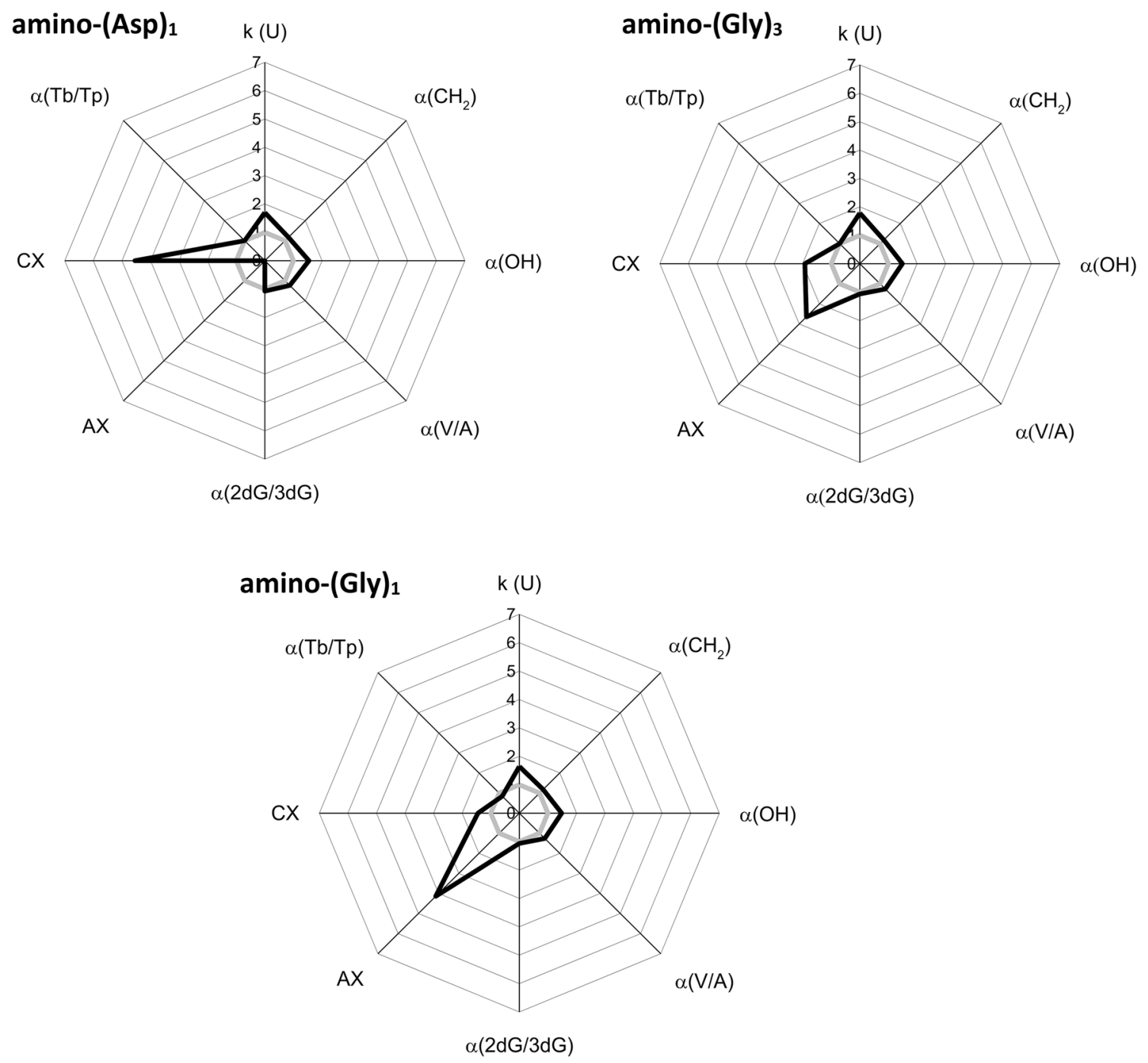

Fig. 2 (continued)

residual silanols act as cation-exchange functionality. The anion-exchange capability which is an anticipated feature of this type of materials was observed for all the tested columns except the amino-(Asp) $)_{1}$ phase.

Despite the same core of chemically bonded ligands, the differences in side chains of amino acids and a variation of surface heterogeneity indicate assorted applicability of the investigated columns. Based on the performed research, the following column classification may be performed [30]. As for the selection of cationic-type column-all the studied stationary phases with exception of amino-(Asp) ${ }_{1}$, should provide sufficient retention of acidic compounds. As regards the separation targets, changing particular tested columns for another one may provide modification of the separation selectivity. However, it should be emphasized that the application of basic stationary phases will decrease of separation efficiency as a consequence of ion-exchange interactions.
Thus, the selection of neutral peptide-based columns constitutes a better choice for acidic compounds under adequate retention requirements. An advantage of the amino acid- and peptide-silica stationary phases is their capability to create of secondary interactions, i.e. proton-donor and protonacceptor interactions, $\pi-\pi$ interactions, and apparent electrostatic interactions. This multivariate system may produce higher selectivity, even specificity of different separation targets.

The investigated stationary phases can have limited application for analyzing basic compounds due to a considerable effect of the residual silanols on the retention mechanism. Nevertheless, the amino-(Asp) ${ }_{1}$ phase, which exhibits a zwitterionic nature of bonded functionality and considerable cation-exchange capabilities, may be a propitious choice to achieve sufficient retention of these separation targets. In the case of other materials, the optimization of salt 
concentration, the type of buffer, and the $\mathrm{pH}$ of mobile phase should be investigated to eliminate the undesirable effect of residual silanols. The simplest separation targets comprise globally neutral compounds. For this purpose, each of the prepared stationary phases is capable of providing adequate retention in HILIC conditions. Nevertheless, it should be mentioned that the above statements arise from the initial study of the stationary phases with chemically bonded amino acids and peptides. Thus, there is a need for further evaluation of their applicability.

\section{Principal Component Analysis}

The data presented in the form of radar plots were also analyzed by means of factor analysis (FA). The factors in FA were calculated based on principal component analysis (PCA). According to the eigenvalue-one criterion, two principal components have been taken into consideration. These factors were then rotated using the normalized Varimax method. The model with the two first principal components explained more than $85 \%$ of cumulative variance. The score plot of the tested stationary phases in the space of the first two components is presented in Fig. 3. The factor loadings are listed in Table 7, highlighted loading values being greater than 0.7 .

The score plot shows that the tested stationary phases were divided into two groups. One group contains stationary phases with chemically bonded hydrophilic amino acids and peptides and the second one includes columns containing in the structure amino acids and peptides with hydrophobic side chains. Therefore, the type of amino acid side chains discriminated the classification of the tested stationary phases. According to Table 7, factor 1 is related mainly to parameters describing ion-exchange interactions

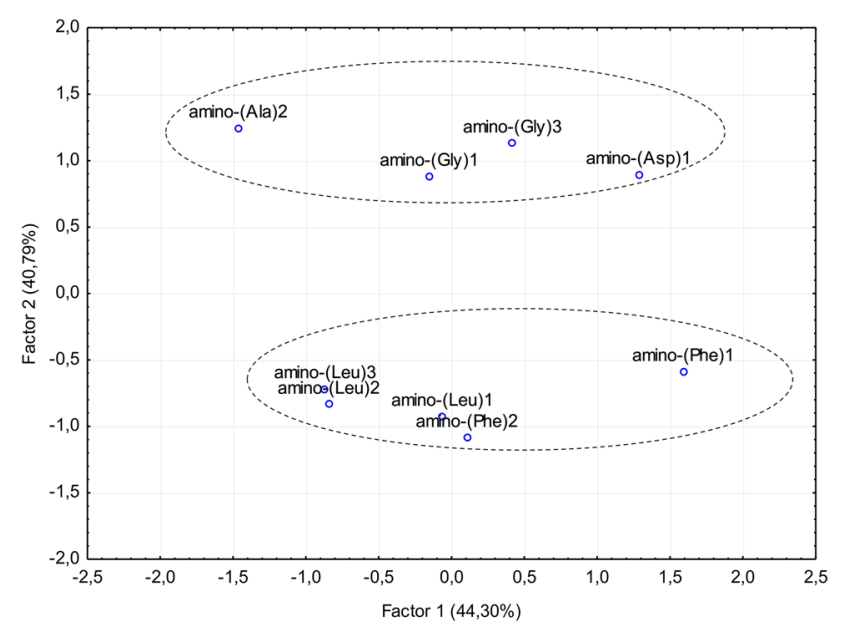

Fig. 3 The stationary phase comparison by PCA score plot. The explained variance of particular factors are written in brackets
Table 7 Factor loadings structure

\begin{tabular}{lrc}
\hline Variable & Factor 1 & Factor 2 \\
\hline$\alpha\left(\mathrm{CH}_{2}\right)$ & 0.06 & $\mathbf{0 . 8 8}$ \\
$\alpha(\mathrm{OH})$ & -0.05 & $\mathbf{0 . 9 4}$ \\
$\alpha(\mathrm{V} / \mathrm{A})$ & -0.49 & $\mathbf{0 . 7 3}$ \\
$\alpha(2 \mathrm{dG} / 3 \mathrm{dG})$ & $\mathbf{0 . 8 3}$ & 0.34 \\
$\alpha(\mathrm{AX})$ & $-\mathbf{0 . 9 1}$ & 0.13 \\
$\alpha(\mathrm{CX})$ & $\mathbf{0 . 9 3}$ & -0.16 \\
$\alpha(\mathrm{Tb} / \mathrm{Tp})$ & 0.61 & $\mathbf{0 . 7 7}$ \\
Eigenvalue & 3.10 & 2.86 \\
\hline
\end{tabular}

and regioisomerism. Among these parameters, the anionexchange interactions are negatively correlated, while the others indicate the positive correlation. Thus, the weaker anion-exchange properties of the stationary phase, the higher factor 1 value could be observed (Fig. 3). The factor 2 is loaded mainly with parameters related to hydrophilic and hydrophobic interactions, as well as the $\mathrm{pH}$ of the stationary phase surface and configurational isomerism. In this case, all of the highlighted values indicated a positive correlation. In this regard, the significant $\alpha(\mathrm{OH})$ and $\alpha\left(\mathrm{CH}_{2}\right)$ contribution to factor 2 loadings induced that primarily this principal component classified the tested column into two groups based on their hydrophilic and hydrophobic properties.

On the other hand, factor 1 may divide columns according to their surface heterogeneity due to the appreciable impact of cation-exchange interactions (caused by residual silanols). Nevertheless, it should be kept in mind the amino-(Asp) phase exhibits cation-exchange capability due to also the presence of carboxyl group in the side chain. Indeed, this column is located at high positive value of factor 1 . The similar position of amino-(Phe) ${ }_{1}$ phase on the score plot (Fig. 3) with regard to factor 1 is, on the other hand, related with the presence of significant amount of residual silanols (Table 1).

\section{RP-Mode Characterization of Stationary Phases}

The characterization of the stationary phases containing amino acids and peptides with hydrophobic side chains were also performed under RP conditions and it is given in Online Source.

\section{The Carbohydrates Separation}

To present the influence of the amino acids type on the separation under HILIC conditions, the selected stationary phases were also applied to carbohydrates and polyols separation. The obtained results are shown in Fig. 4. The elongation of aminopropyl ligand with dipeptide of alanine [amino-(Ala $)_{2}$, Fig. 4b] and tripeptide of glycine [amino-(Gly) ${ }_{3}$, Fig. 4c] induced the higher selectivity for 

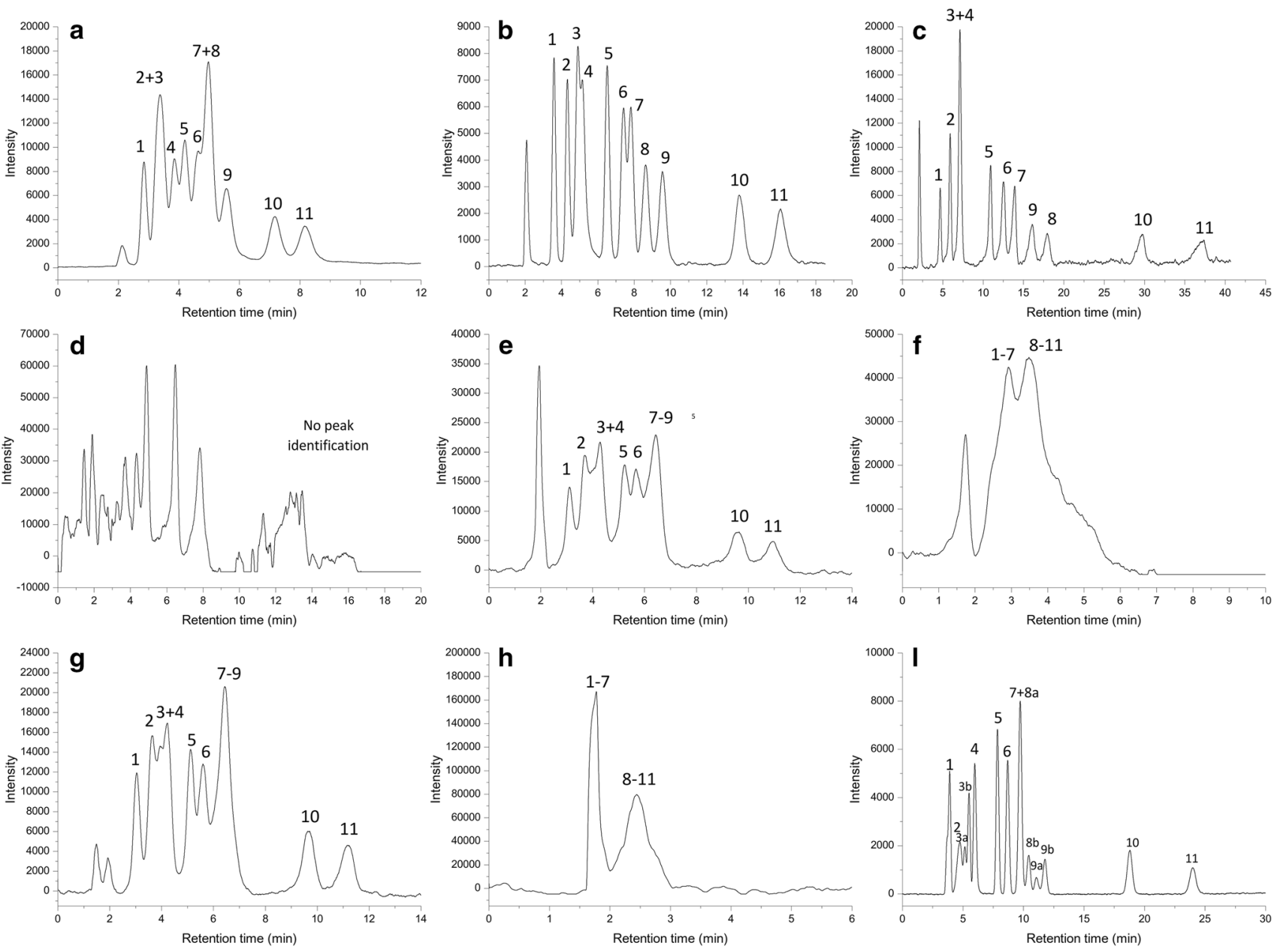

Fig. 4 Carbohydrates separation on the selected amino acid- and peptide-silica stationary phases: a silica-Amino, b amino-(Ala) ${ }_{2}$, c amino-(Gly $)_{3}$, d amino-(Asp) ${ }_{1}$, e amino-(Leu $)_{1}$, f amino-(Leu $)_{2}, \mathbf{g}$ amino-(Phe $)_{1}$, h amino-(Phe $)_{2}$, i ObeliscN. Separated compounds: 1 D-(+)-xylose, 2 D-(-)-fructose, 3 D-(+)-glucose, 4 D-sorbitol, 5 L-(-)-chiro-inositol, 6 sucrose, 7 myo-inositol, 8 D-(+)-maltose,
$9 \alpha$-lactose, $10 \mathrm{D}$-(+)-melezitose, $11 \mathrm{D}$-(+)-raffinose (concentration $\left.0.1 \mathrm{mg} \mathrm{mL}^{-1}\right)$. Conditions: mobile phase $\mathrm{ACN} / \mathrm{H}_{2} \mathrm{O}\left(85: 15_{\mathrm{v} / \mathrm{v}}\right)$,

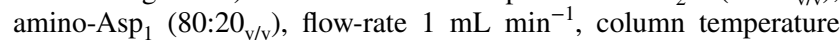
$30{ }^{\circ} \mathrm{C}$, sample volume $10 \mu \mathrm{L}$ ELSD: heated drift tube temperature of ELSD: $50{ }^{\circ} \mathrm{C}$, gas pressure: 3.24 bar, gain: 7

It can be assumed that the longer sequence of amino acids containing hydrophobic side chains, the lower selectivity is caused. Indeed, the stationary phases with bonded hydrophobic amino acids (classified according to their side chain properties) have limited application under HILIC conditions.

Besides of the selectivity improvement, particularly in the case of amino-(Gly) 3 column, it was also observed that the tested stationary phases do not differentiate carbohydrates anomers. This feature is characteristic for the amino-based stationary phases and constitutes their advantage with regard to other columns dedicated for carbohydrates separation. The commercial column Obelisc $\mathrm{N}$ exhibits selectivity for $\alpha$ and $\beta$-sugars (Fig. 4i), which is undesirable effect. However, this problem can be overcome by the appropriate sample preparation or analysis 
conditions [39]. This requirement is not essential in the case of the tested stationary phases due to the presence of the weak alkaline amino groups.

\section{Conclusions}

Stationary phases containing glycine, alanine, and aspartic acid in amino acids sequence demonstrated higher hydrophilic retention than modifications with leucine and phenylalanine. These correlations were in compliance with the hydrophilic/hydrophobic nature of bonded amino acids. The discrimination of configurational isomers was comparable for all the investigated stationary phases, while for the regioisomers it was slightly distinguished by materials with immobilized hydrophilic amino acids and peptides. The anion-exchange capability was observed for all the tested columns except the stationary phase with aspartic acid. Moreover, this feature results particularly from the appearance of the primary amino group, whereas the length of bonded ligand was negligible. The exception was the stationary phase with immobilized aspartic acid molecule which exhibits extremely high cation-exchange capability with reduced anion-exchange interactions. The carboxyl group in the side chain of such amino acid acts as cation-exchange functionality, simultaneously causing the electrostatic repulsion with anionic compound.

The data collected were presented as radar shaped plots and in tabular format with distinguishing particular features of the tested stationary phases. The principal component analysis leads to grouping the tested columns on the basis of their hydrophilic and hydrophobic properties. The first components describes ion-exchange capability of the tested columns, while the second component was loaded with parameters related to hydrophilic and hydrophobic interactions.

Stationary phases with chemically bonded hydrophobic amino acids and peptides (leucine and phenylalanine) demonstrated also the RP-compatible character. The retention of hydrophobic solutes increased with the elongation of peptide chain. The steric selectivity was slightly higher for single amino acid modification compared to peptide ligands.

Thus, it becomes evident how the sequence of amino acids-its type and length-influences the overall chromatographic properties. This format may comprise convenient approach for column selection depending on HILIC or RP HPLC separation targets.

Acknowledgements This work was financially supported by the National Science Center as a part of the PRELUDIUM 12 project No. 2016/23/N/ST4/00369. The authors thank Dr. Szymon Bocian and Dr. Tomasz Kowalkowski for their meaningful suggestions and discussions.

\section{Compliance with Ethical Standards}

Conflict of interest The authors declare that there are no conflicts of interest associated with the manuscript.

Ethical approval This article does not contain any studies with human participants or animals performed by any other authors.

Open Access This article is distributed under the terms of the Creative Commons Attribution 4.0 International License (http://creativeco mmons.org/licenses/by/4.0/), which permits unrestricted use, distribution, and reproduction in any medium, provided you give appropriate credit to the original author(s) and the source, provide a link to the Creative Commons license, and indicate if changes were made.

\section{References}

1. Li J, Li Y, Chen T et al (2013) Preparation, chromatographic evaluation and comparison between linear peptide- and cyclopeptidebonded stationary phases. Talanta 109:152-159

2. Jandera P, Janas P (2017) Recent advances in stationary phases and understanding of retention in hydrophilic interaction chromatography. A review. Anal Chim Acta 967:12-32

3. Bocian S, Skoczylas M, Buszewski B (2015) Amino acids, peptides, and proteins as chemically bonded stationary phases-a review. J Sep Sci 39:83-92

4. Grushka E, Scott RPW (1973) Polypeptides as a permanently bound stationary phase in liquid chromatography. Anal Chem 45:1626-1632

5. Fong GW-K, Grushka E (1977) High-pressure liquid chromatography of amino acids and dipeptides on a tripeptide bonded stationary phase. J Chromatogr A 142:299-309

6. Hagestam IH, Pinkerton TC (1985) Internal surface reversedphase silica supports for liquid chromatography. Anal Chem 57:1757-1763

7. Pinkerton TC (1991) High-performance liquid chromatography packing materials for the analysis of small molecules in biological matrices by direct injection. J Chromatogr A 544:13-23

8. Shen A, Guo Z, Cai X et al (2012) Preparation and chromatographic evaluation of a cysteine-bonded zwitterionic hydrophilic interaction liquid chromatography stationary phase. J Chromatogr A 1228:175-182

9. Nesterenko PN, Kebets PA (2007) Ion-exchange properties of silica gel with covalently bonded histidine. J Anal Chem 62:2-7

10. Nesterenko EP, Nesterenko PN, Paull B (2009) Zwitterionic ionexchangers in ion chromatography: A review of recent developments. Anal Chim Acta 652:3-21

11. Chen Y, Yu D-H (1993) Poly $\left(N^{5}\right.$-benzyl-1-glutamine)-coated silica gels as chiral stationary phase for direct resolution of hydantoins. J Appl Polym Sci 49:851-861

12. Shundo A, Sakurai T, Takafuji M et al (2005) Molecular-length and chiral discriminations by $\beta$-structural poly(L-alanine) on silica. J Chromatogr A 1073:169-174

13. Huang J, Zhang P, Chen H, Li T (2005) Preparation and evaluation of proline-based chiral columns. Anal Chem 77:3301-3308

14. Ohyama K, Oyamada K, Kishikawa N et al (2008) Preparation and characterization of poly(L-phenylalanine) chiral stationary phases with varying peptide length. J Chromatogr A 1208:242-245

15. Xue M, Huang H, Ke Y et al (2009) "Click dipeptide": a novel stationary phase applied in two-dimensional liquid chromatography. J Chromatogr A 1216:8623-8629 
16. Ray S, Takafuji M, Ihara H (2012) A new peptide-silica bioinspired stationary phase with an improved approach for hydrophilic interaction liquid chromatography. Analyst 137:4907-4909

17. Ray S, Takafuji M, Ihara $\mathrm{H}$ (2012) Chromatographic evaluation of a newly designed peptide-silica stationary phase in reverse phase liquid chromatography and hydrophilic interaction liquid chromatography: mixed mode behavior. J Chromatogr A 1266:43-52

18. Buszewski B, Gadzala-Kopciuch RM, Markuszewski M, Kaliszan R (1997) Chemically bonded silica stationary phases: synthesis, physicochemical characterization and molecular mechanism of reversed phase HPLC retention. Anal Chem 69:3277-3284

19. Claessens H, van Straten M, Cramers C et al (1998) Comparative study of test methods for reversed-phase columns for high-performance liquid chromatography. J Chromatogr A 826:135-156

20. Buszewski B, Jezierska M, Wełniak M, Kaliszan R (1999) Cholesteryl-silica stationary phase for liquid chromatography: comparative study on retention behavior and selectivity. J Chromatogr A 845:433-445

21. Buszewski B, Jezierska-Switala M, Kaliszan R et al (2001) Selectivity tuning and molecular modeling of new generation packings for RP HPLC. Chromatographia 53:204-212

22. Neue UD, Van Tran K, Iraneta PC, Alden BA (2003) Characterization of HPLC packings. J Sep Sci 26:174-186

23. Lesellier E, West C (2007) Description and comparison of chromatographic tests and chemometric methods for packed column classification. J Chromatogr A 1158:329-360

24. Schuster G, Lindner W (2013) Comparative characterization of hydrophilic interaction liquid chromatography columns by linear solvation energy relationships. J Chromatogr A 1273:73-94

25. Kimata K, Iwaguchi K, Onishi S et al (1989) Chromatographic characterization of silica $\mathrm{C} 18$ packing materials. Correlation between a preparation method and retention behavior of stationary phase. J Chromatogr Sci 27:721-728

26. Kawachi Y, Ikegami T, Takubo H et al (2011) Chromatographic characterization of hydrophilic interaction liquid chromatography stationary phases: Hydrophilicity, charge effects, structural selectivity, and separation efficiency. J Chromatogr A 1218:5903-5919

27. Dolci M (2013) Chromatographic characterization of stationary phases for hydrophilic interaction liquid chromatography. Technical Note 20741

28. Lämmerhofer M, Richter M, Wu J et al (2008) Mixed-mode ion-exchangers and their comparative chromatographic characterization in reversed-phase and hydrophilic interaction chromatography elution modes. J Sep Sci 31:2572-2588

29. Dinh NP, Jonsso T, Irgum K (2011) Probing the interaction mode in hydrophilic interaction chromatography. J Chromatogr A 1218:5880-5891

30. Chirita R-I, West C, Finaru A-L, Elfakir C (2010) Approach to hydrophilic interaction chromatography column selection: application to neurotransmitters analysis. J Chromatogr A 1217:3091-3104

31. Poole CF, Poole SK (2002) Column selectivity from the perspective of the solvation parameter model. J Chromatogr A 965:236-299

32. Vitha M, Carr PW (2006) The chemical interpretation and practice of linear solvation energy relationships in chromatography. $\mathrm{J}$ Chromatogr A 1126:143-194

33. Jandera P, Hájek T, Škeřiková V, Soukup J (2010) Dual hydrophilic interaction-RP retention mechanism on polar columns: Structural correlations and implementation for 2-D separations on a single column. J Sep Sci 33:841-852

34. Chirita R-I, West C, Zubrzycki S et al (2011) Investigations on the chromatographic behaviour of zwitterionic stationary phases used in hydrophilic interaction chromatography. J Chromatogr A 1218:5939-5963

35. Skoczylas M, Bocian S, Buszewski B (2016) Dipeptide-bonded stationary phases for hydrophilic interaction liquid chromatography. Rsc Adv 6:96389-96397

36. Skoczylas M, Bocian S, Kowalkowski T, Buszewski B (2017) The effect of solvation processes on amino acid- and peptide-silica stationary phases. J Sep Sci 40:4152-4159

37. Bocian S, Matyska M, Pesek J, Buszewski B (2010) Study of the retention and selectivity of cholesterol bonded phases with different linkage spacers. J Chromatogr A 1217:6891-6897

38. Bispo MS, Veloso MCC, Pinheiro HLC et al (2002) Simultaneous determination of caffeine, theobromine, and theophylline by highperformance liquid chromatography. J Chromatogr Sci 40:46-48

39. Dvořačkova E, Šnõblová M, Hrdlička P (2014) Carbohydrate analysis: from sample preparation to HPLC on different stationary phases coupled with evaporative light-scattering detection. J Sep Sci 37:323-337 